\title{
Screening for New Pathways in Atmospheric Oxidation Chemistry with Automated Mechanism
}

\section{Generation}

\section{Supporting Information}

\author{
Victoria P. Barber ${ }^{1 *}$, William H. Green ${ }^{2}$, and Jesse H. Kroll ${ }^{1}$ \\ ${ }^{1}$ Department of Civil and Environmental Engineering \\ ${ }^{2}$ Department of Chemical Engineering \\ Massachusetts Institute of Technology, Cambridge, MA 02139 \\ *corresponding author, email: vbarber@mit.edu
}

Table of Contents

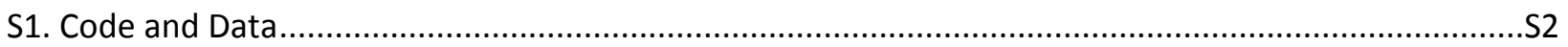

S2. Uncategorized reactions in the "uncanonical" filtered dataset ........................................................S2

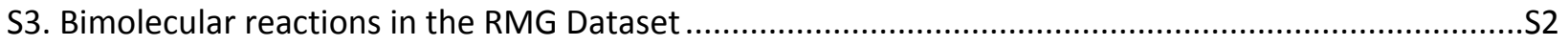

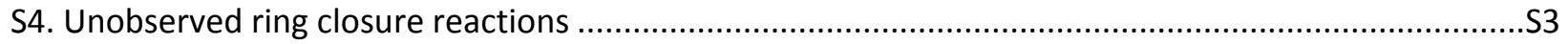

S5. Outliers in Figure 8

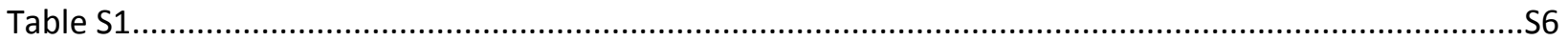

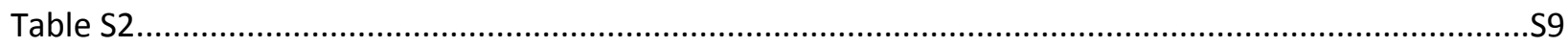

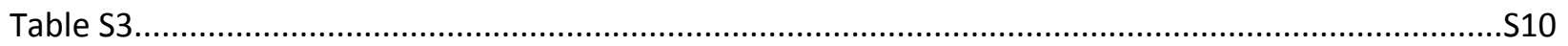

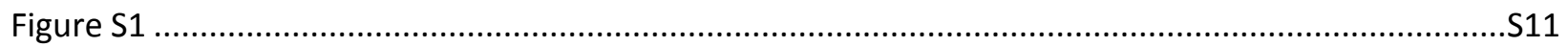

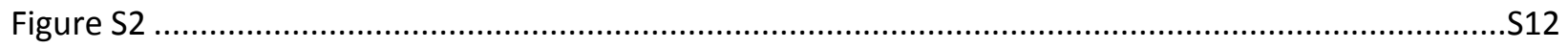

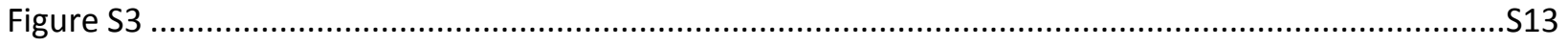

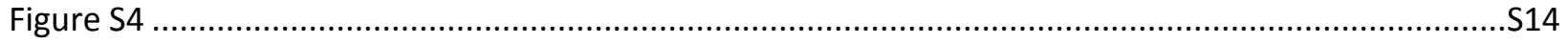

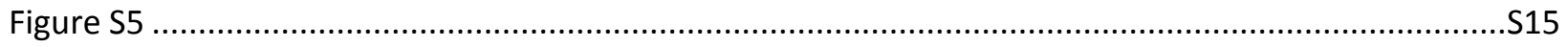

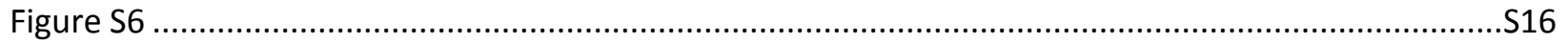

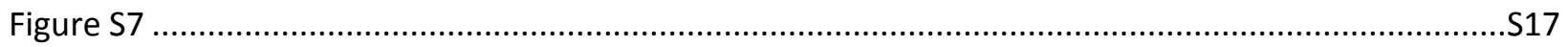




\section{S1. Code and Data}

Data, including RMG input files and RMG chemkin files and species dictionaries for model cores and edges, and code associated with the filtering algorithm are available here. Please contact the authors if you would like to use any data or code herein in a publication.

\section{S2. Uncategorized reactions in the "uncanonical" filtered dataset}

As discussed in the main text, there are 54 reactions that do not belong to any of the categories presented. Here, we briefly discuss each of these reactions, which are illustrated in Figure S5. The summary statistics associated with each of these reactions are presented in Table S3.

The majority of the remaining reactions involve $\mathrm{O}_{2}$ additions to oxygen-centered $\left(\mathrm{RO}\right.$ and $\left.\mathrm{RO}_{2}\right)$ radicals, Reactions $\mathrm{S} 1$ and $\mathrm{S} 2$ in Figure $\mathrm{S} 5$, respectively). The $\mathrm{RO}+\mathrm{O}_{2}$ reaction yields an $\mathrm{RO}_{3}$ radical and appears 12 times in the dataset. On top of being rather slow compared to other alkoxy radical removal pathways (with an average $\mathrm{k} / \mathrm{k}_{\text {total }}$ of 0.02 ), this reaction has been proposed previously, and is thought to lead to the same $\mathrm{HO}_{2}+$ carbonyl products as the typical $\mathrm{H}$-atom abstraction pathway for alkoxy radicals. ${ }^{1,2}$ It is thus unlikely to be of consequence. Similarly, we also see an $\mathrm{RO}_{2}+\mathrm{O}_{2}$ reaction that yields an $\mathrm{RO}_{4}$ radical product, which appears 15 times in the dataset. Interestingly, this reaction only seems to be available for acyl peroxy radicals. The RMG results suggest a relatively low mean $\mathrm{k} / \mathrm{k}_{\text {total }}$ of $10^{-2}$. Additionally, the reverse reaction rate constant is predicted to be on the order of $10^{13} \mathrm{~s}^{-1}$, and absent an extremely fast (unknown) alternative removal process of the $\mathrm{RO}_{4}$, its most likely fate is dissociation back to $\mathrm{RO}_{2}$ and $\mathrm{O}_{2}$. This pathway is therefore expected to be of minimal importance.

Reactions S3 and S4 in Figure S5 are keto-enol tautomerization-like reactions, analogous to Reaction 12 in Figure 3 of the main text, but for $\mathrm{RO}_{2}$ and $\mathrm{R}$ radicals. There is only one such example in the dataset for $\mathrm{RO}_{2}$ (Reaction S4 in Figure S4); interestingly, this reaction does not create a resonance stabilized radical, and accordingly is much slower, with a rate of $0.07 \mathrm{~s}^{-1}$ and a $\mathrm{k} / \mathrm{k}_{\text {total }}$ of 0.08 . There are 2 examples of such reactions for $\mathrm{R}$ radicals (Reaction S5 in Figure S5), which do create resonance stabilized radicals. Here, the average rate is on the order of $10^{5} \mathrm{~s}^{-1}$, but since these reactions involve $\mathrm{R}$ radicals and compete with much fast processes, the $\mathrm{k} / \mathrm{k}_{\text {total }}$ is still quite low, with an average value of $5.2 \times 10^{-4}$ and again are unlikely to be important pathways.

Reaction S5 in Figure S5 is a fragmentation of an acyl R radical to yield a new R radical and a CO cofragment, which appears 20 times in the dataset. This reaction is well-known in combustion systems, ${ }^{3}$ and has also been proposed for some atmospheric systems, ${ }^{4}$ but is not typically considered in standard atmospheric oxidation mechanisms, where acyl $\mathrm{R}$ radicals are typically assumed to react with $\mathrm{O}_{2}$ to yield acyl peroxy radicals. Interestingly, many of these fragmentation reactions are quite fast, with an average $\mathrm{k}$ on the order of $10^{8} \mathrm{~s}^{-1}$ and an average $\mathrm{k} / \mathrm{k}_{\text {total }}$ of 0.6 . None of the fragmentation reactions that appear in the dataset involve the production of simple, unsubstituted $\mathrm{R}$ radicals. Rather, in all cases, the $\mathrm{R}$ radical product of the fragmentation is either a new, smaller acyl radical, a resonance stabilized radical, or a radical $\alpha$ to another oxygenated functional group like an alcohol or ether. This suggests that when certain functional groups are present on acyl radicals, the fragmentation is competitive with $\mathrm{O}_{2}$ addition and may deserve further attention.

The remaining 5 reactions in the dataset are "one-off" reactions. They each appear only 1 or 2 times in the reaction dataset. For completeness, these reactions are included in Figure S5, but because of the inherent uncertainty associated with predicting single rate constants through RMG, it is not practical to make conclusions about these reactions or their potential importance in the atmosphere.

S3. Bimolecular reactions in the RMG Dataset 
Radical-Radical reactions are treated separately in the fast filtering algorithm. First, we calculate a $\mathrm{k}_{\text {total }}$ Here, $k_{\text {total }}$ is used in the same way as defined in Section 2 of the main text and refers to the sum of the unimolecular reaction rate constants of $\mathrm{X}$, the pseudo-first order reaction rate constants with $\mathrm{O}_{2}$ and (for $\mathrm{RO}_{2}$ radicals), the pseudo-first order reaction rates with $\mathrm{NO}$ and $\mathrm{HO}_{2} . \mathrm{k}_{\text {total }}$ does not include reactions between organic radicals, or radical-radical reactions predicted by RMG. As with other reactions, we then use the criteria that:

$$
\frac{\mathrm{k}_{\mathrm{XY}}[\mathrm{X}][\mathrm{Y}]}{\mathrm{k}_{\mathrm{total}}[\mathrm{X}]}>10^{-4} \#(1)
$$

Where $\mathrm{k}_{\mathrm{XY}}$ is the bimolecular rate constant and $[\mathrm{X}]$ and $[\mathrm{Y}]$ are the concentrations of species $\mathrm{X}$ and $\mathrm{Y} .10^{-4}$ is the same low-cutoff factor discussed in Section $2 \mathrm{~B}$ of the main text. Rearranging the expression yields:

$$
\frac{\mathrm{k}_{\mathrm{XY}}}{\mathrm{k}_{\text {total }}}>\frac{10^{-4}}{[\mathrm{Y}]} \#(2)
$$

Which is the expression used in the fast filtering to decide which bimolecular reactions are included in the dataset. Note that $\mathrm{k}_{\mathrm{XY}} / \mathrm{k}_{\text {total, }}$, in contrast to the $\mathrm{k} / \mathrm{k}_{\text {total }}$ referenced in the main text, is not a unitless quantity, because $k_{\text {total }}$ is a pseudo-first order removal rate constant, while $k_{x y}$ is a second order rate constant. Here, $[\mathrm{Y}]$ is unknown, and so it is used as another variable in the filtering algorithm. $[\mathrm{Y}]$ is treated as a "concentration cutoff", and should be thought of as the maximum possible concentration of the radical reaction partner. If the concentration cutoff is a high value, then slower reactions (with lower $k_{X Y}$ values) should make it past the fast filtering step. On the other hand, if the concentration cutoff is lower, then the threshold for a bimolecular reaction to be considered "fast" is higher. In this work, we use a concentration cutoff of $10^{-9} \mathrm{~mol} / \mathrm{m}^{3}$, approximately equivalent to the total VOC concentration in the input to RMG. This value is conservatively high, as it is unlikely that any individual radical should have such a high concentration at any point in time. $4.1 \times 10^{3}$ bimolecular reactions of $\mathrm{R}, \mathrm{RO}$, and $\mathrm{RO}_{2}$ are found to meet this fast filtering criteria. No additional filtering is performed to determine whether these reactions are "uncanonical".

In Figure $\mathrm{S} 1$, the distribution of $\mathrm{k}_{\mathrm{XY}} / \mathrm{k}_{\text {total }}$ of the radical-radical reactions that make it past the fast filtering step is shown. To further assess the potential importance of these radical-radical reactions, one can consider what value of $[Y]$ would be needed in order for rate $e_{x y}$ to be equivalent to $10 \%$ of rate total $_{\text {. This }}$ value of $[\mathrm{Y}]$ is referred to as $[\mathrm{Y}]_{0}$ and is plotted on the upper $\mathrm{X}$-axis of Figure $\mathrm{S} 1$.

$$
\mathrm{k}_{\mathrm{XY}}[\mathrm{Y}]_{0}=0.1 \times \mathrm{k}_{\text {total }} \#(3)
$$

From Figure S1, it can be seen that the large majority of the radical-radical reactions would need reaction partner concentrations greater than $10^{-11} \mathrm{~mol} / \mathrm{m}^{3}$, or on the order of $1 \mathrm{ppt}$ in order to compete with unimolecular and $\mathrm{O}_{2}$ reaction removal pathways. While there are some cases where radical concentrations may be high enough, or rate constants fast enough, for reactions between organic radicals to be a significant loss process, these cases are relatively rare. These cases may be a target for future work, but here we restrict our discussion to unimolecular reactions and reactions with $\mathrm{O}_{2}$.

\section{S4. Unobserved ring closure reactions}

As discussed in the main text, only a few reactions are found for 3, 4, and 7 membered unsaturated radical ring closure (Reactions 2-4 in Figure 3). In general, when reactions show up only rarely in the 
filtered dataset, there are two possible explanations: either the reactant radical that allows for such a reaction is rarely encountered in the network generation process, or the reactant radical is available, but the reaction rates are too slow to make it past the "fast" filtering step. In the case of the 3-membered ring, for which only 4 reactions are encountered, the first explanation applies. The necessary reactant radical (which involves a peroxy radical moiety bonded to an $\mathrm{sp}^{2}$ hybridized carbon involved in a carboncarbon double bond) is not frequently encountered in the reaction networks. However, there exists significant theoretical and experimental evidence that this 3-membered ring closure reaction, which RMG suggests is quite fast, is a major pathway in $\mathrm{OH}$-initiated oxidation of alkynes, ${ }^{5}$ which are not included in the initial set of species considered.

A similar explanation holds true for the 7-membered ring case; because each reactant compound is only 5 carbons, the formation of a 7-membered ring with an endocyclic radical center is only available for primary peroxy radicals with a terminal alkene on the opposite terminus of the molecule (no exocyclic radical formation is available in this case), a condition which is satisfied only for a small subset of species in the dataset. It is still feasible that the reaction could be atmospherically important, though it is hard to infer from such a small sample of these reactions.

For the 4-membered ring case however, the explanation is somewhat different. In this case, endocyclic radical formation would involve the same kind of $\mathrm{sp}^{2}$ carbon bound peroxy radical as described in the 3membered ring case and therefore is not often encountered in the dataset. However, even if it were, it's likely most of these reactions would be too slow to make it through the "fast" filtering step due to strain associated with the formation of 4 membered rings. On the other hand, there is no inherent reason why the reactant radical for the exocyclic radical formation, which involves a peroxy radical alpha to the carbon-carbon double bond, should not be encountered in the dataset. Instead, the majority of the 4membered ring, exocyclic radical formation reactions are too slow relative to other removal pathways to make it through the filtering algorithm. Based on the RMG results, these 4-membered cyclizations are likely at most a minor atmospheric pathway.

\section{S5. Outliers in Figure 8}

Figure 8 in the main text shows the rates of reaction for the ring-opening reactions of the oxydioxane radicals (Reaction 9 in Figure 3). In the uncanonical reaction dataset, there are $2 \mathrm{C}-\mathrm{C}$ bond breaking reactions forming esters that are predicted to have rate constants on the order of $10^{23} \mathrm{~s}^{-1}$, many orders of magnitude higher than the remaining predicted rate constants for Reaction 9 . These reaction rates are predicted based on the rate of the reverse ring-closing reaction in RMG. In the version of RMG used in this work (version 3.0.0, accessed March 18, 2020), these two ring-closing reactions are predicted by RMG to have an activation energy of $29.7 \mathrm{kcal} / \mathrm{mol}$. Since then, RMG has been updated and the predicted activation energy for the ring-closing has increased dramatically, to $40.5 \mathrm{kcal} / \mathrm{mol}$, resulting in much slower ring opening reaction rate of $10^{14} \mathrm{~s}^{-1}$, on the order of the other ring opening reactions in Figure 8 . Hence, the outliers have been removed from the Figure.

\section{References}

1. Jungkamp, T. P. W.; Smith, J. N.; Seinfeld, J. H. Atmospheric Oxidation Mechanism of $\mathrm{n}$-Butane: The Fate of Alkoxy Radicals. J. Phys. Chem. A 1997, 101, 4392-4401.

2. Deng, W.; Wang, C.; Katz, D. R.; Gawinski, G. R.; Davis, A. J.; Dibble, T. S. Direct Kinetic Studies of the Reactions of 2-Butoxy Radicals with $\mathrm{NO}$ and $\mathrm{O}_{2}$. Chem. Phys. Lett. 2000, 330, 541-546.

3. Tsang, W.; Hampson, R. F. Chemical Kinetic Data Base for Combustion Chemistry. Part I. Methane and Related Compounds. J. Phys. Chem. Ref. Data 1986, 15, 1087-1279. 
4. Crounse, J. D.; Knap, H. C.; Ørnsø, K. B.; Jørgensen, S.; Paulot, F.; Kjaergaard, H. G.; Wennberg, P. O. Atmospheric Fate of Methacrolein. 1. Peroxy Radical Isomerization Following Addition of $\mathrm{OH}$ and $\mathrm{O}_{2}$. J. Phys. Chem. A 2012, 116, 5756-5762.

5. Yeung, L. Y.; Pennino, M. J.; Miller, A. M.; Elrod, M. J. Kinetics and Mechanistic Studies of the Atmospheric Oxidation of Alkynes. J. Phys. Chem. A 2005, 109, 1879-1889.

6. Vereecken, L.; Nozière, B. H Migration in Peroxy Radicals under Atmospheric Conditions. Atmos. Chem. Phys. 2020, 20, 7429-7458. 
Table S1: List of all molecules for which $\mathrm{OH}$-initiated oxidation reaction networks were generated in RMG. "Number" refers to carbon number of the groups listed in the "Functional" column, in order.

\begin{tabular}{|c|c|c|c|}
\hline Functional & Number & Functional & Number \\
\hline Alcohol & 1 & Alcohol_Hydroperoxide & $1 \_4$ \\
\hline Alcohol & 2 & Alcohol_Hydroperoxide & 1_5 \\
\hline Alcohol & 3 & Alcohol_Hydroperoxide & $2 \_1$ \\
\hline Carbonyl & 1 & Alcohol_Hydroperoxide & $2 \_2$ \\
\hline Carbonyl & 2 & Alcohol_Hydroperoxide & $2 \_3$ \\
\hline Carbonyl & 3 & Alcohol_Hydroperoxide & $2 \_4$ \\
\hline Hydroperoxide & 1 & Alcohol_Hydroperoxide & $2 \_5$ \\
\hline Hydroperoxide & 2 & Alcohol_Hydroperoxide & 3_1 \\
\hline Hydroperoxide & 3 & Alcohol_Hydroperoxide & $3 \_2$ \\
\hline Alkene & 1 & Alcohol_Hydroperoxide & $3 \_3$ \\
\hline Alkene & 2 & Alcohol_Alkene & 1_1 \\
\hline Ether & 2 & Alcohol_Alkene & $1 \_2$ \\
\hline Ether & 3 & Alcohol_Alkene & 1_3 \\
\hline Alkoxy & 1 & Alcohol_Alkene & $1 \_4$ \\
\hline Alkoxy & 2 & Alcohol_Alkene & $2 \_1$ \\
\hline Alkoxy & 3 & Alcohol_Alkene & $2 \_2$ \\
\hline Alcohol_Alcohol & 1_1 & Alcohol_Alkene & $2 \_3$ \\
\hline Alcohol_Alcohol & $1 \_2$ & Alcohol_Alkene & $2 \_4$ \\
\hline Alcohol_Alcohol & 1_3 & Alcohol_Alkene & 3_1 \\
\hline Alcohol_Alcohol & $1 \_4$ & Alcohol_Alkene & $3 \_2$ \\
\hline Alcohol_Alcohol & $1 \_5$ & Ether_Alcohol & 1_1 \\
\hline Alcohol_Alcohol & $2 \_2$ & Ether_Alcohol & $1 \_2$ \\
\hline Alcohol_Alcohol & $2 \_3$ & Ether_Alcohol & $1 \_3$ \\
\hline Alcohol_Alcohol & 244 & Ether_Alcohol & 1_4 \\
\hline Alcohol_Alcohol & 3_3 & Ether_Alcohol & $2 \_1$ \\
\hline Carbonyl_Alcohol & 1_1 & Ether_Alcohol & $2 \_2$ \\
\hline Carbonyl_Alcohol & $1 \_2$ & Ether_Alcohol & $2 \_3$ \\
\hline Carbonyl_Alcohol & $1 \_3$ & Ether_Alcohol & $2 \_4$ \\
\hline Carbonyl_Alcohol & $1 \_4$ & Ether_Alcohol & 3_1 \\
\hline Carbonyl_Alcohol & $1 \_5$ & Ether_Alcohol & $3 \_2$ \\
\hline Carbonyl_Alcohol & $2 \_1$ & Alkoxy_Alcohol & $1 \_1$ \\
\hline Carbonyl_Alcohol & $2 \_3$ & Alkoxy_Alcohol & $1 \_2$ \\
\hline Carbonyl_Alcohol & $2 \_4$ & Alkoxy_Alcohol & $1 \_3$ \\
\hline Carbonyl_Alcohol & $2 \_5$ & Alkoxy_Alcohol & $1 \_4$ \\
\hline Carbonyl_Alcohol & 3_1 & Alkoxy_Alcohol & $1 \_5$ \\
\hline Carbonyl_Alcohol & $3 \_2$ & Alkoxy_Alcohol & $2 \_1$ \\
\hline Alcohol_Hydroperoxide & 1_1 & Alkoxy_Alcohol & $2 \_2$ \\
\hline Alcohol_Hydroperoxide & $1 \_2$ & Alkoxy_Alcohol & $2 \_3$ \\
\hline Alcohol_Hydroperoxide & $1 \_3$ & Alkoxy_Alcohol & $2 \_4$ \\
\hline
\end{tabular}




\begin{tabular}{|c|c|c|c|}
\hline Alkoxy_Alcohol & $2 \_5$ & Alkoxy_Carbonyl & 3_1 \\
\hline Alkoxy_Alcohol & $3 \_2$ & Hydroperoxide_Hydroperoxide & 1_1 \\
\hline Alkoxy_Alcohol & 3_3 & Hydroperoxide_Hydroperoxide & $1 \_2$ \\
\hline Carbonyl_Carbonyl & 1_4 & Hydroperoxide_Hydroperoxide & 1_3 \\
\hline Carbonyl_Carbonyl & $1 \_5$ & Hydroperoxide_Hydroperoxide & 1_4 \\
\hline Carbonyl_Carbonyl & $2 \_3$ & Hydroperoxide_Hydroperoxide & 1_5 \\
\hline Carbonyl_Carbonyl & $2 \_4$ & Hydroperoxide_Hydroperoxide & $2 \_2$ \\
\hline Carbonyl_Hydroperoxide & 1_1 & Hydroperoxide_Hydroperoxide & $2 \_3$ \\
\hline Carbonyl_Hydroperoxide & $1 \_2$ & Hydroperoxide_Hydroperoxide & $2 \_4$ \\
\hline Carbonyl_Hydroperoxide & 1_3 & Hydroperoxide_Hydroperoxide & 3_3 \\
\hline Carbonyl_Hydroperoxide & 1_4 & Alkene_Hydroperoxide & 1_1 \\
\hline Carbonyl_Hydroperoxide & $1 \_5$ & Alkene_Hydroperoxide & 1_2 \\
\hline Carbonyl_Hydroperoxide & $2 \_1$ & Alkene_Hydroperoxide & $1 \_3$ \\
\hline Carbonyl_Hydroperoxide & $2 \_3$ & Alkene_Hydroperoxide & $1 \_4$ \\
\hline Carbonyl_Hydroperoxide & $2 \_4$ & Alkene_Hydroperoxide & $2 \_1$ \\
\hline Carbonyl_Hydroperoxide & $2 \_5$ & Alkene_Hydroperoxide & $2 \_2$ \\
\hline Carbonyl_Hydroperoxide & 3_1 & Alkene_Hydroperoxide & $2 \_3$ \\
\hline Carbonyl_Hydroperoxide & $3 \_2$ & Alkene_Hydroperoxide & 3_1 \\
\hline Carbonyl_Alkene & $1 \_2$ & Alkene_Hydroperoxide & $3 \_2$ \\
\hline Carbonyl_Alkene & $1 \_3$ & Ether_Hydroperoxide & 1_1 \\
\hline Carbonyl_Alkene & $1 \_4$ & Ether_Hydroperoxide & $1 \_2$ \\
\hline Carbonyl_Alkene & $2 \_3$ & Ether_Hydroperoxide & $1 \_3$ \\
\hline Carbonyl_Alkene & 244 & Ether_Hydroperoxide & $1 \_4$ \\
\hline Carbonyl_Alkene & 3_1 & Ether_Hydroperoxide & $2 \_1$ \\
\hline Carbonyl_Ether & 1_1 & Ether_Hydroperoxide & $2 \_2$ \\
\hline Carbonyl_Ether & $1 \_2$ & Ether_Hydroperoxide & $2 \_3$ \\
\hline Carbonyl_Ether & $1 \_3$ & Ether_Hydroperoxide & $2 \_4$ \\
\hline Carbonyl_Ether & $1 \_4$ & Ether_Hydroperoxide & 3_1 \\
\hline Carbonyl_Ether & $2 \_1$ & Ether_Hydroperoxide & $3 \_2$ \\
\hline Carbonyl_Ether & $2 \_2$ & Alkoxy_Hydroperoxide & 1_1 \\
\hline Carbonyl_Ether & $2 \_3$ & Alkoxy_Hydroperoxide & $1 \_2$ \\
\hline Carbonyl_Ether & 244 & Alkoxy_Hydroperoxide & $1 \_3$ \\
\hline Carbonyl_Ether & 3_1 & Alkoxy_Hydroperoxide & $1 \_4$ \\
\hline Carbonyl_Ether & $3 \_2$ & Alkoxy_Hydroperoxide & 1_5 \\
\hline Alkoxy_Carbonyl & 1_1 & Alkoxy_Hydroperoxide & $2 \_1$ \\
\hline Alkoxy_Carbonyl & $1 \_2$ & Alkoxy_Hydroperoxide & $2 \_2$ \\
\hline Alkoxy_Carbonyl & 1_3 & Alkoxy_Hydroperoxide & $2 \_3$ \\
\hline Alkoxy_Carbonyl & $1 \_4$ & Alkoxy_Hydroperoxide & $2 \_4$ \\
\hline Alkoxy_Carbonyl & $1 \_5$ & Alkoxy_Hydroperoxide & $2 \_5$ \\
\hline Alkoxy_Carbonyl & $2 \_1$ & Alkoxy_Hydroperoxide & 3_1 \\
\hline Alkoxy_Carbonyl & $2 \_3$ & Alkoxy_Hydroperoxide & $3 \_2$ \\
\hline Alkoxy_Carbonyl & $2 \_4$ & Alkoxy_Hydroperoxide & 3_3 \\
\hline Alkoxy_Carbonyl & $2 \_5$ & Alkene_Alkene & 1_3 \\
\hline
\end{tabular}




\begin{tabular}{|c|c|c|}
\hline Alkene_Alkene & $1 \_4$ & \\
\hline Ether_Alkene & $1 \_2$ & \\
\hline Ether_Alkene & 1_3 & \\
\hline Ether_Alkene & $1 \_4$ & \\
\hline Ether_Alkene & $2 \_3$ & \\
\hline Ether_Alkene & $2 \_4$ & \\
\hline Ether_Alkene & $3 \_4$ & \\
\hline Alkoxy_Alkene & 1_1 & \\
\hline Alkoxy_Alkene & $1 \_2$ & \\
\hline Alkoxy_Alkene & 1_3 & \\
\hline Alkoxy_Alkene & $1 \_4$ & \\
\hline Alkoxy_Alkene & $2 \_1$ & \\
\hline Alkoxy_Alkene & $2 \_2$ & \\
\hline Alkoxy_Alkene & $2 \_3$ & \\
\hline Alkoxy_Alkene & $2 \_4$ & \\
\hline Alkoxy_Alkene & 3_1 & \\
\hline Alkoxy_Alkene & $3 \_2$ & \\
\hline Ether_Ether & 1_1 & \\
\hline Ether_Ether & $1 \_2$ & \\
\hline Ether_Ether & $1 \_3$ & \\
\hline Ether_Ether & $1 \_4$ & \\
\hline Ether_Ether & $2 \_2$ & \\
\hline Ether_Ether & $2 \_3$ & \\
\hline Alkoxy_Ether & 1_1 & \\
\hline Alkoxy_Ether & $1 \_2$ & \\
\hline Alkoxy_Ether & 1_3 & \\
\hline Alkoxy_Ether & $1 \_4$ & \\
\hline Alkoxy_Ether & 2_1 & \\
\hline Alkoxy_Ether & $2 \_2$ & \\
\hline Alkoxy_Ether & $2 \_3$ & \\
\hline Alkoxy_Ether & $2 \_4$ & \\
\hline Alkoxy_Ether & 3_1 & \\
\hline Alkoxy_Ether & $3 \_2$ & \\
\hline
\end{tabular}


Table S2: Starting mole fractions for RMG reaction network generation. The same parameters are used for each starting organic species.

\begin{tabular}{cc}
\hline Species & Mole Fraction \\
\hline Organic & $5 \times 10^{-9}$ \\
$\mathrm{OH}$ & $5 \times 10^{-13}$ \\
$\mathrm{O}_{2}$ & 0.2 \\
$\mathrm{~N}_{2}$ & 0.8 \\
\hline
\end{tabular}


Table S3: Summary statistics associated with the more minor reaction categories presented in Figure S5.

\begin{tabular}{|c|c|c|c|c|c|c|}
\hline & $\begin{array}{l}\text { Reaction } \\
\text { Category }\end{array}$ & $\mathrm{N}$ & $\begin{array}{c}\text { Geometric } \\
\text { Mean (k) } \\
\mathrm{s}^{-1}\end{array}$ & $\begin{array}{c}\text { Geometric Standard } \\
\text { Deviation (k) }\end{array}$ & $\begin{array}{c}\text { Arithmetic } \\
\text { Mean } \\
\left(\mathrm{k} / \mathrm{k}_{\text {total }}\right), \mathrm{s}^{-1}\end{array}$ & $\begin{array}{l}\text { Arithmetic } \\
\sigma\left(\mathrm{k} / \mathrm{k}_{\text {total }}\right)\end{array}$ \\
\hline S1 & $\mathrm{RO}+\mathrm{O}_{2}$ to $\mathrm{RO}_{3}$ & 12 & $9.9 \times 10^{1}$ & 8.8 & $1.9 \times 10^{-2}$ & $5.2 \times 10^{-2}$ \\
\hline $\mathrm{S} 2$ & $\mathrm{RO}_{2}+\mathrm{O}_{2}$ to $\mathrm{RO}_{4}$ & 15 & $3.1 \times 10^{-1}$ & 10 & $6.0 \times 10^{-2}$ & $5.4 \times 10^{-2}$ \\
\hline S3 & Acyl $R$ to $R+C O$ & 19 & $6.3 \times 10^{8}$ & $4.2 \times 10^{3}$ & 0.57 & 0.45 \\
\hline S4 & $\begin{array}{c}\text { Bicyclic } R \\
\text { fragmentation }\end{array}$ & 2 & $1.1 \times 10^{14}$ & 4.5 & 0.33 & 0.21 \\
\hline S5 & $\begin{array}{c}\mathrm{RO}_{2} \\
\text { fragmentation }\end{array}$ & 1 & $4.3 \times 10^{-5}$ & - & $1.8 \times 10^{-3}$ & - \\
\hline S6 & See Figure S5 & 2 & $7.8 \times 10^{6}$ & 1.2 & 0.24 & 0.32 \\
\hline
\end{tabular}




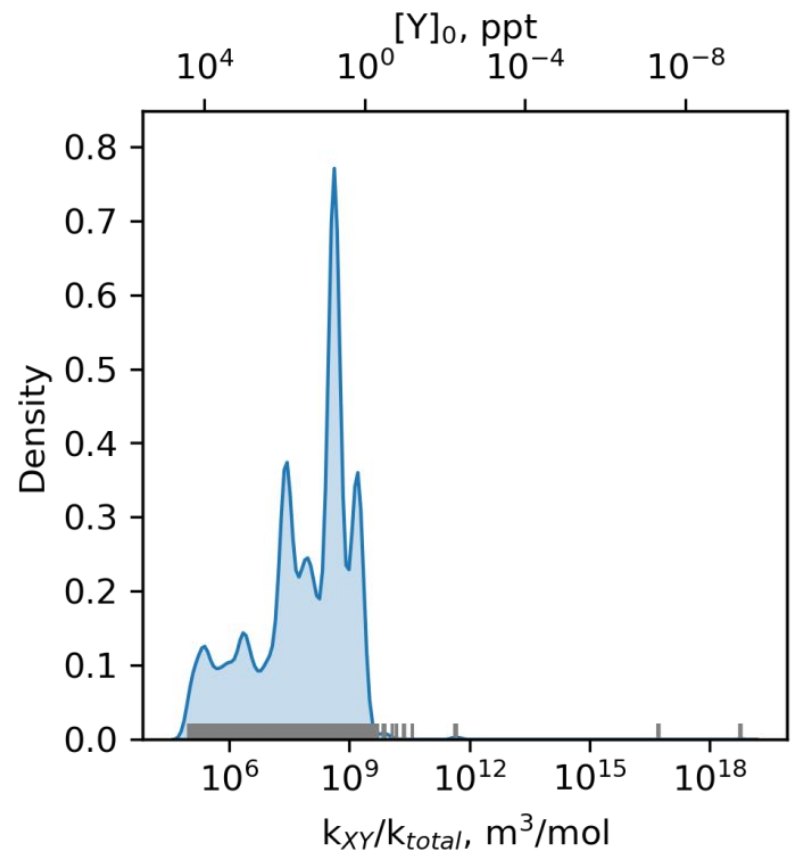

Figure S1: Gaussian kernel density estimate for the distribution of $\mathrm{k}_{\mathrm{xy}} / \mathrm{k}_{\text {total }}$ for radical-radical reactions in the filtered dataset. Here, $\mathrm{k}_{\text {total }}$ refers to the sum of the unimolecular rate constants for species $\mathrm{X}$ and pseudo first order rates of reaction with $\mathrm{O}_{2}$ and (in the case of $\mathrm{RO}_{2}$ radicals) $\mathrm{HO}_{2}$ and $\mathrm{NO}$. The top axis shows the value of $[\mathrm{Y}],[\mathrm{Y}]_{0}$, needed for the radical-radical reaction rate to be equal to $10 \%$ of the rate associated with $\mathrm{k}_{\text {total }}$. Short gray lines on the bottom axis represent individual rate constant predictions. 
Aldehyde
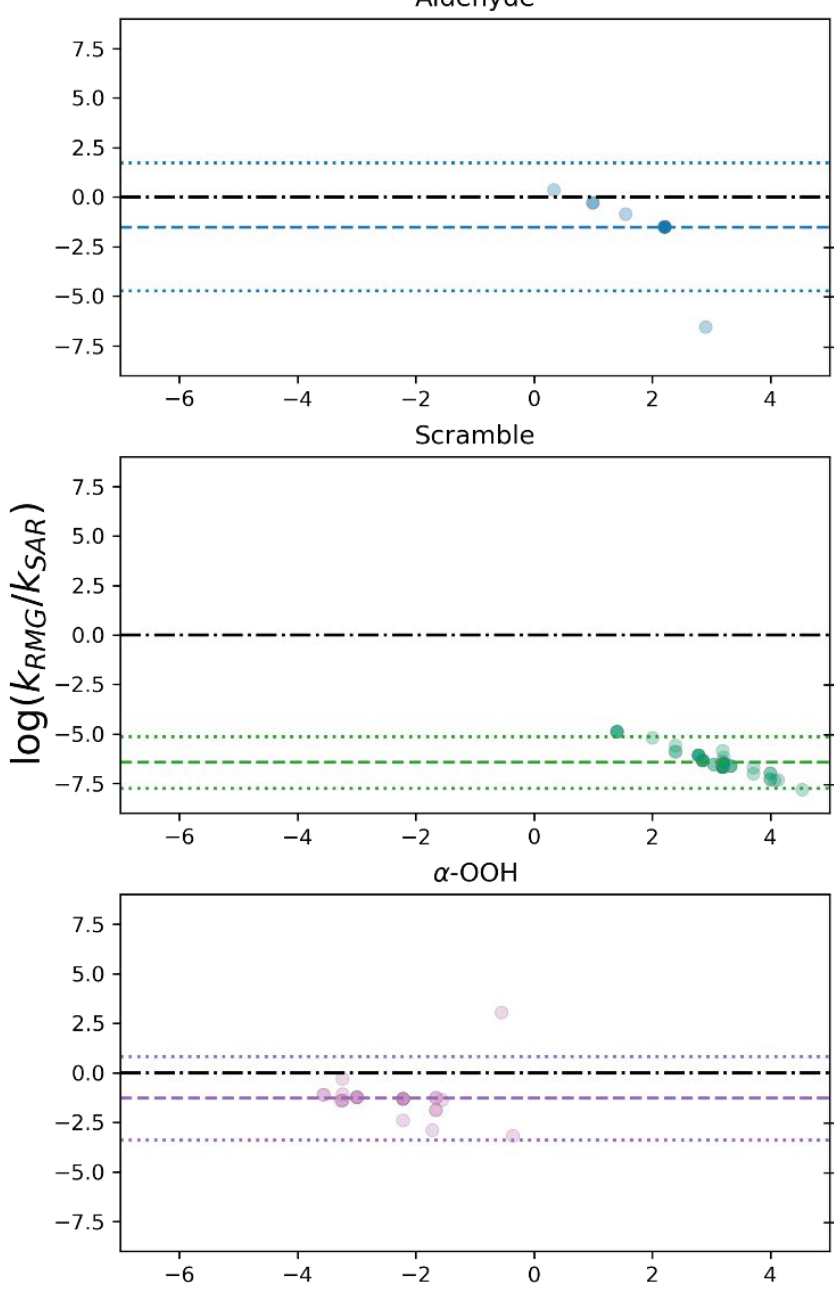

Aliphatic
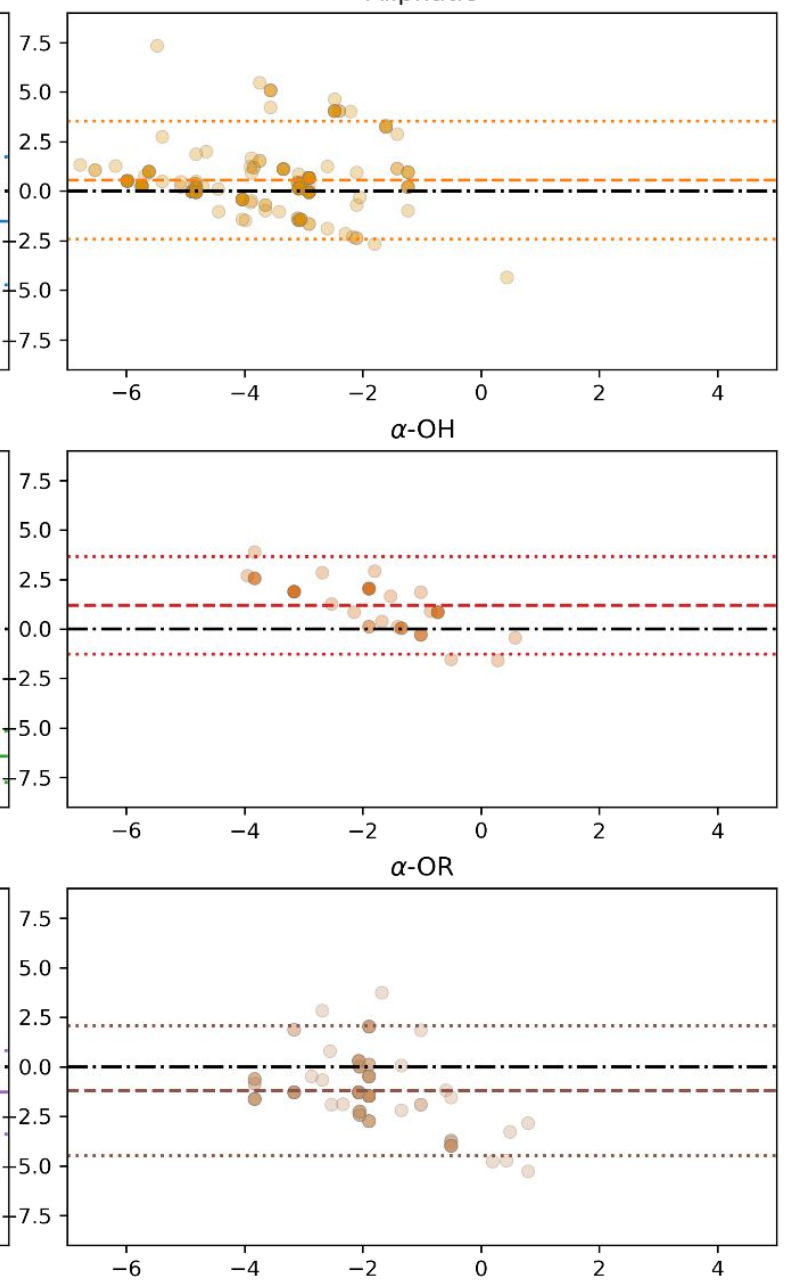

$\log \left(k_{S A R}\right)$

Figure S2: Logarithmic plot of the ratio of the RMG predicted rate constant $\left(k_{R M G}\right)$ to the SAR predicted rate constant $\left(\mathrm{k}_{\mathrm{SAR}}\right)^{6}$, for all of the $\mathrm{H}$-atom shift reactions of mono and bifunctionally substituted $\mathrm{RO}_{2}$ radicals in the filtered RMG dataset, as a function of $\mathrm{k}_{\text {SAR }}$. Each point represents an individual unique $\mathrm{H}$ atom shift reaction. Points are partly transparent, so that a darker colored point indicates multiple overlapping points. Each subplot represents a H-atom shift category, where the category is defined according to the substituent on the carbon that bears the hydrogen shifted in the reaction, as shown in Figure 5 of the main text. A point falling at a $k_{R M G} / k_{S A R}$ of 1 (black, dot-dashed line) represents a reaction for which the RMG and SAR predictions are equivalent. Within each category of H-atom shift, we show the mean of $\log \left(\mathrm{k}_{\mathrm{RMG}} / \mathrm{k}_{\mathrm{SAR}}\right)$ (central dashed colored line), and a $95 \%$ confidence interval associated with this ratio (outer dotted colored lines) assuming a normal distribution. 


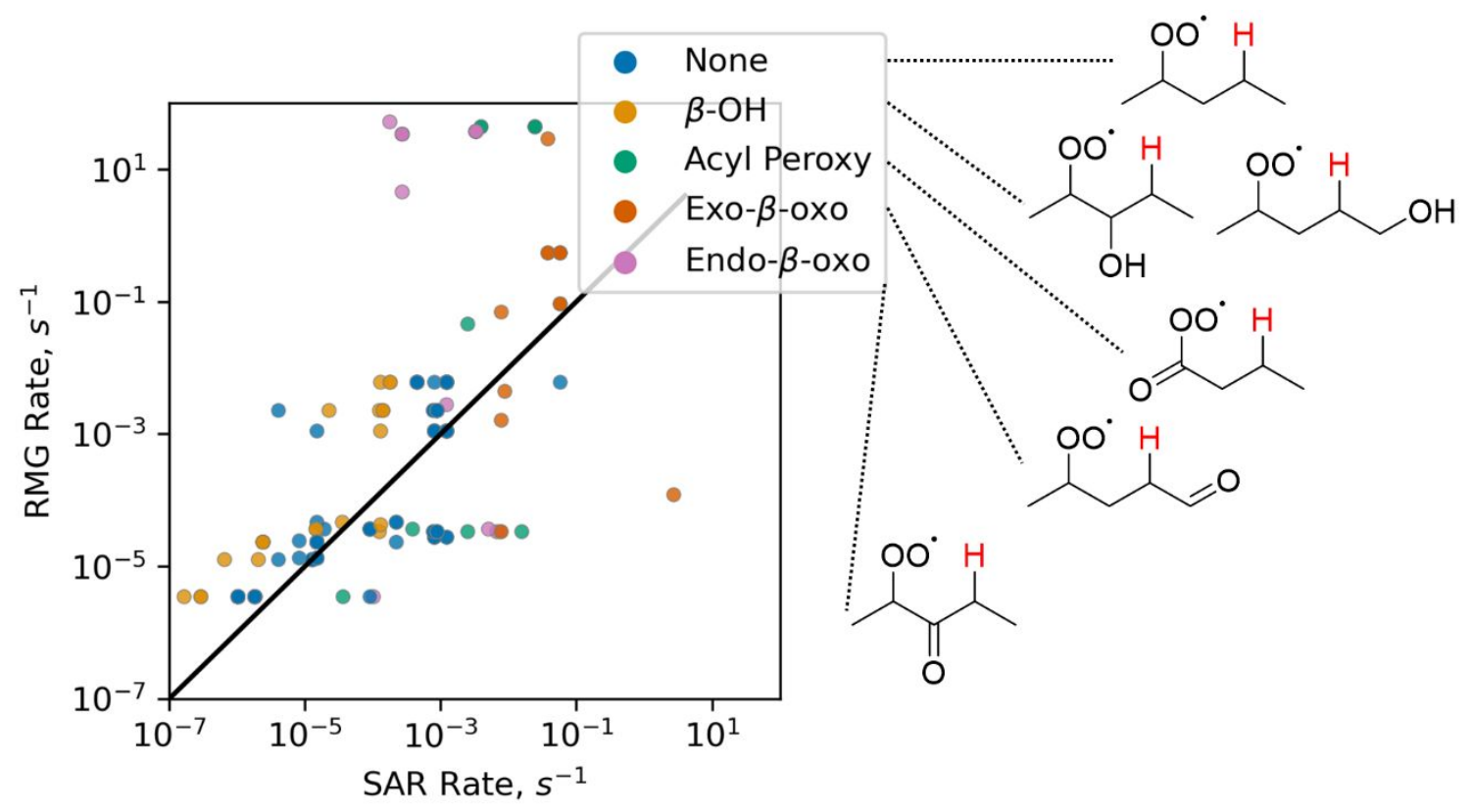

Figure S3: RMG-predicted rate constants associated with the $\mathrm{RO}_{2} \mathrm{H}$-shifts for mono- and bifunctionally substituted $\mathrm{RO}_{2}$ radicals with no substituent on the carbon that bears the shifting hydrogen (referred to as " $\alpha$-unsubstituted" in Figure 5 of the main text. The RMG-predicted rates are plotted as a function of the SAR-predicted rate $^{6}$ for the same reaction. The solid black line is a 1:1 line, representing equivalent RMG and SAR rate constants. The points are colored according to the presence of secondary substituents as shown to the right of the graph; the chemical structure for a simple reactant $\mathrm{RO}_{2}$ radical for each category is shown, and the red $\mathrm{H}$-atom in each structure represents the atom undergoing the intramolecular hydrogen transfer reaction. 


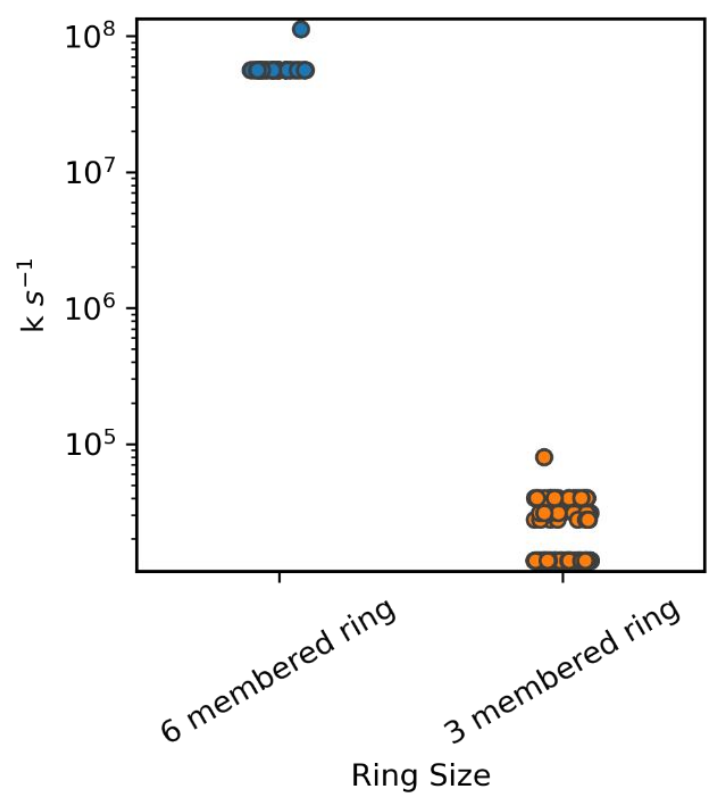

Figure S4: Rate constants for cyclic ether formation (Reaction 1 in Figure 3) from the filtered RMG dataset, sorted according to the size of the resulting ring. Each point represents an individual rate constant. 


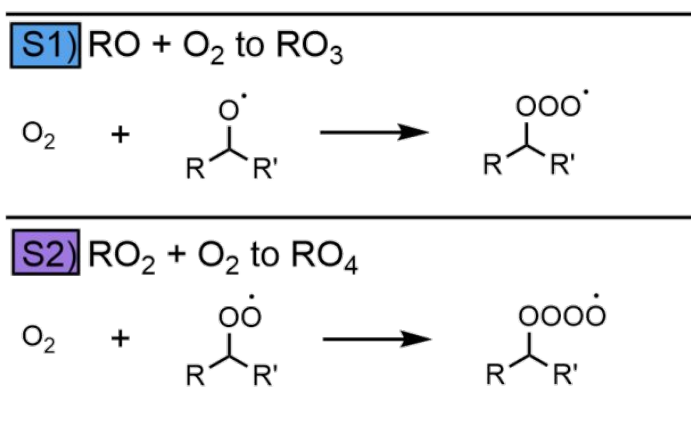

S3) Acyl R to R + CO
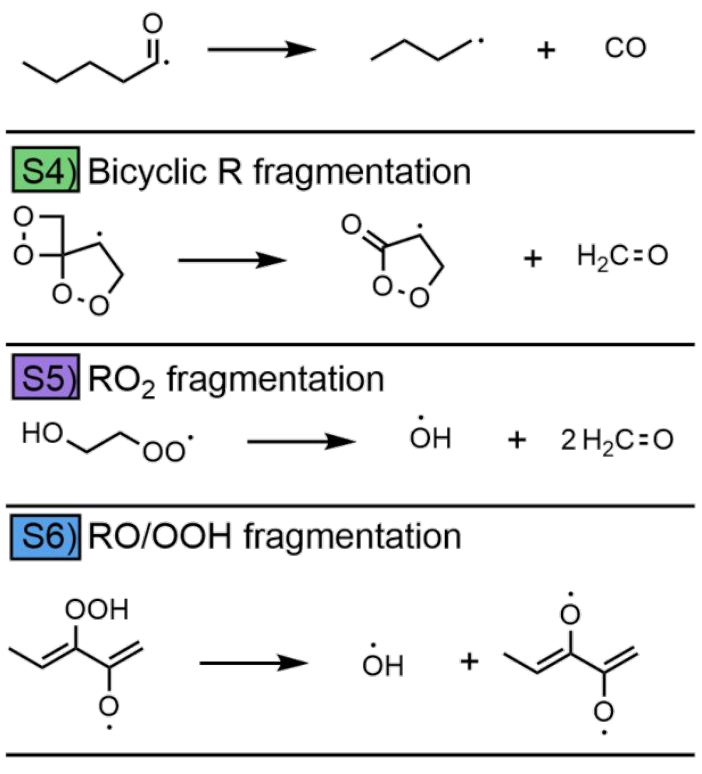

Figure S5: Supplementary reactions in the filtered RMG dataset. Reaction numbers are colored according to whether reactants are $\mathrm{R}$ (green), $\mathrm{RO}$ (blue) or $\mathrm{RO}_{2}$ (purple) radicals. 

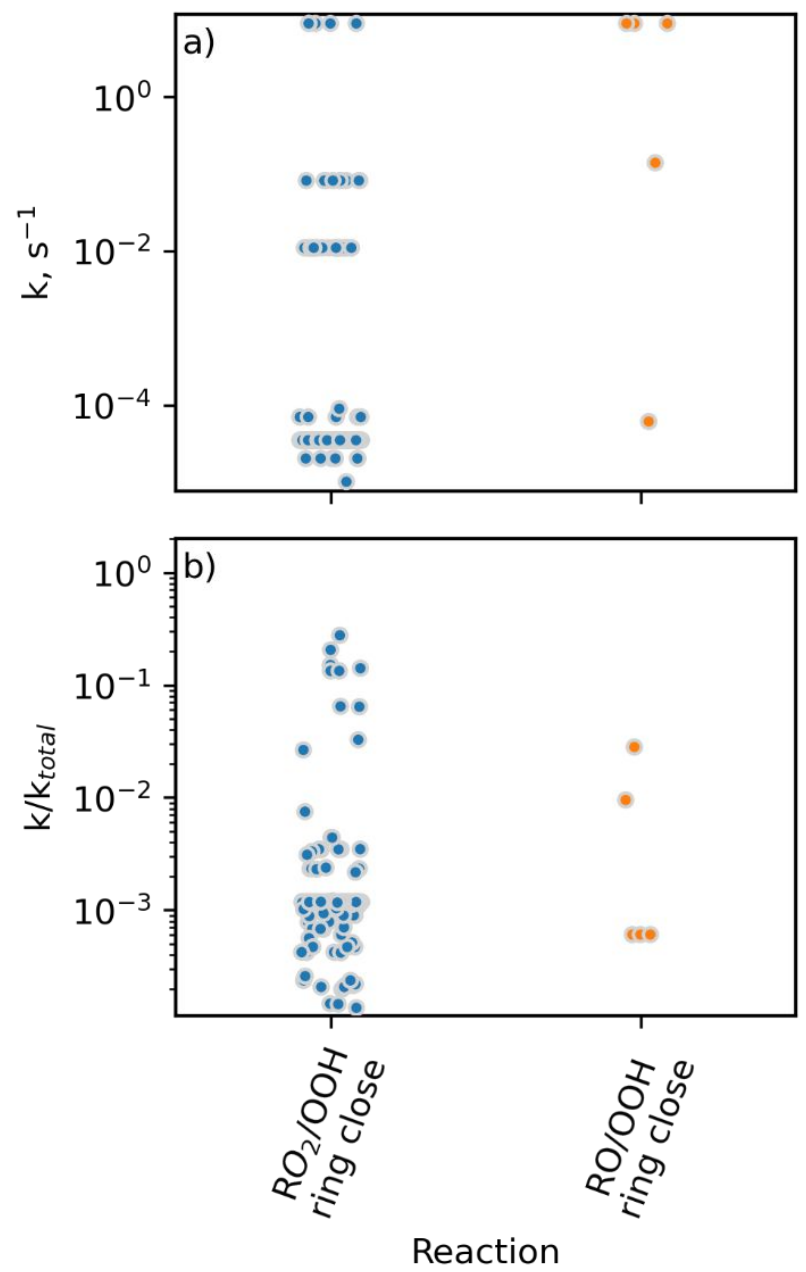

Figure S6: Rate constants (a) and $\mathrm{k} / \mathrm{k}_{\text {total }}$ ratios (b) for the $\mathrm{RO}_{2} / \mathrm{OOH}$ cyclization reaction, which yields a ozonide-like species, and the and $\mathrm{RO} / \mathrm{OOH}$ cyclization reactions, which yields an endocyclic peroxide species. Both reactions also yield an $\mathrm{OH}$ radical coproduct, and are shown as Reactions 10 and 11 in Figure 3 of the main text. 

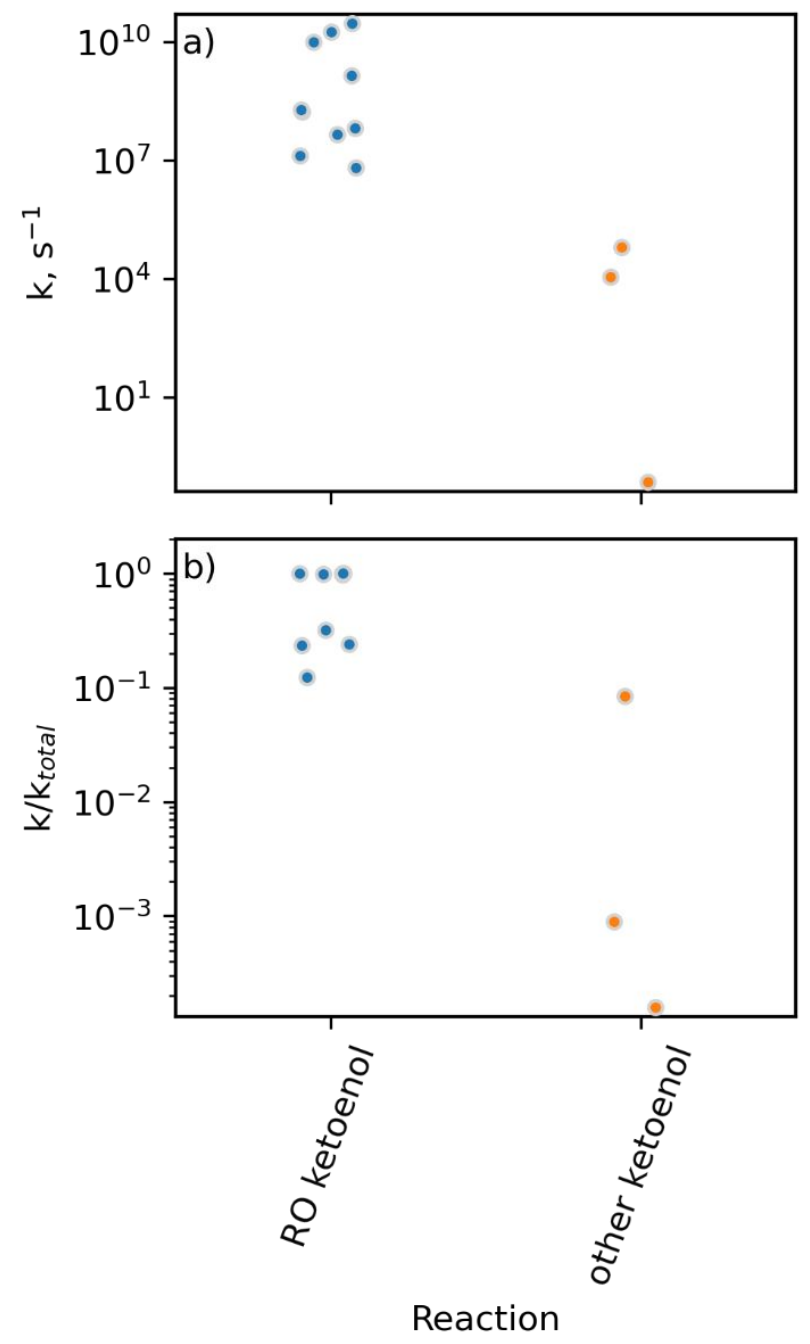

Figure S7: Rate constants (a) and $\mathrm{k} / \mathrm{k}_{\text {total }}$ ratios (b) for the keto-enol tautomerization reaction of a $\beta$ carbonyl substituted RO radical (RO keto-enol), shown as Reaction 12 in Figure 3 of the main text, as well as for the several additional keto-enol tautomerization reactions encountered in the filtered RMG dataset. 